\title{
Investigation of TEC and VLF space measurements associated to L'Aquila (Italy) earthquakes
}

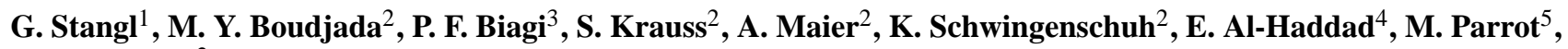 \\ and W. Voller ${ }^{2}$ \\ ${ }^{1}$ Federal Office of Metrology and Surveying, Vienna, Austria \\ ${ }^{2}$ Space Research Institute, Austrian Academy of Sciences, Graz, Austria \\ ${ }^{3}$ Department of Physics, University of Bari, Bari, Italy \\ ${ }^{4}$ Software Engineering, Campus 02, University of Applied Sciences, Graz, Austria \\ ${ }^{5}$ Laboratoire de Physique et Chimie de l'Environnement, Orléans, France
}

Received: 14 October 2010 - Revised: 7 February 2011 - Accepted: 9 February 2011 - Published: 1 April 2011

\begin{abstract}
In this study, we report on Total Electron Content (TEC) and Very Low Frequency (VLF) space measurements derived from Global Positioning System (GPS) and DEMETER satellites, respectively. These measurements are associated with the earthquake (EQ) of a magnitude of 6.3, which occurred on 6 April 2009, in L'Aquila (Italy). Anomaly features are derived from the analysis of TEC and VLF observations recorded two weeks before and after the seismic event occurrence. A TEC map with an interpolated regional pixel resolution of $1^{\circ} \times 1^{\circ} \times 15 \mathrm{~min}$ in latitude, longitude and time was generated, allowing for the checking of a possible presence of disturbances over the L'Aquila region. This analysis is combined with the study of the time profile associated to the VLF flux density variations recorded by the Instrument Champ Electrique (ICE) experiment on-board DEMETER satellite. We discuss, on the one hand, the combination efficiency of the electronic density and the VLF electromagnetic measurements and, on the other hand, the difficulty to distinguish between global effects and regional ones related to the earthquake.
\end{abstract}

\section{Introduction}

Electromagnetic phenomena associated with EQs have been extensively discussed in the literature as reported in Molchanov and Hayakawa (2008). Investigations have shown anomalous increases in the intensity of the electro- magnetic signal received during the period just prior to EQs. Those anomalies also affected the Earth's ionosphere as reviewed by Pulinets and Boyarchuk (2004) who summarized the major characteristic parameters of the observed effects on the basis of hundreds of seismic cases.

\subsection{Ionospheric electron density anomalies}

At the end of the 1900s, space observations showed the presence of electron density anomalies of the ionospheric $F$ region a few days before some strong EQs using topside sounder installed on board orbiting satellites (Pulinets, 1998). This relation has been confirmed by Hayakawa et al. (2000) and Liu et al. (2000) using INTERCOSMOS24 satellite and ground-based local ionosonde observations, respectively. Investigations reported a correlation between global distribution of seismic activity and ion density variations in the ionosphere. The correlation is found only for daytime (10:00-16:00 LT), quiet magnetic conditions and altitude range $500-700 \mathrm{~km}$. The main weakness of the ionosonde technique has been the limited spatial and temporal coverage (Davies, 1990).

The deployment of thousands of ground-based GPS receivers allows us to monitor the Earth's surface deformation rates (Calais and Amarjargal, 2000) and to monitor simultaneously and continuously the ionospheric TEC. The TEC parameter represents the sum of electrons per $\mathrm{m}^{2}$ between the altitude of the satellite and the ground. Therefore, it leads, in particular, to estimating the density in the F layer which is much larger than in the others.

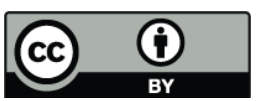

Correspondence to: G. Stangl

(guenter.stangl@oeaw.ac.at)

Published by Copernicus Publications on behalf of the European Geosciences Union. 
The GPS observations have been used to study the variation of TEC before and after EQs. Combining the data of the GPS receivers network, time and spatial variations of TEC prior to the earthquakes have been examined and found that ionospheric disturbances of the TEC were triggered by seismic events. Hence, scientists have reported an apparent reduction in GPS TEC a few days prior to some strong EQs (e.g., Calais and Minster, 1995; Liu et al., 2001, 2002). More recently Akhoondzadeh et al. (2010) and Zhao et al. (2008) reported TEC investigations where the anomalous enhancement occurred in the ionosphere a few days before earthquake occurrences.

\subsection{Detection of VLF natural and transmitters signals above seismic regions}

The discovery of ionospheric perturbations for the Kobe EQ by means of sub-ionospheric VLF monitoring (Hayakawa et al., 1996) indicated that the ionosphere is extremely sensitive to seismic activities. The French DEMETER mission provides a new opportunity to investigate anomalies of the ionosphere related to EQs. This is the first satellite designed specifically for the monitoring of EQs. Molchanov et al. (2006) analysed the variation of the intensity levels of the transmitter signals of ground-based stations as recorded by the electric field (Berthelier et al., 2006) and magnetic field experiments (Parrot et al., 2006) on board DEMETER micro-satellite. They found a drop in the VLF transmitter intensity level above EQs regions in Europe and in Asia.

Later on, investigations confirmed these findings as reported in several papers. Rozhnoi et al. (2007) monitored VLF/LF signals recorded by a ground-based station (Kamchatka, Russia) and others by DEMETER microsatellite. They considered EQs which occurred in the JapanKamchatka region in November-December 2004 and JulySeptember 2005, and showed clear anomalies both in the ground and in satellite data. Muto et al. (2008) followed the method proposed by Molchanov et al. (2006) to analyse Japanese EQs which happened from June to August 2005. They found significant changes in the intensity and, in particular, in the signal-to-noise ratio before the EQ, which is considered to be a precursory ionospheric signature of the EQ. Boudjada et al. $(2008,2010)$ found a similar drop in the natural whistler VLF intensity level a few days before the EQs in the Adriatic region. Using different methods based mainly on the processing of the recorded dynamic spectrum, for each half orbit, authors lead to estimate the maximum of the intensity level through the observed channel frequency of ICE experiment.

\subsection{Nature of the lithosphere-ionosphere interactions}

Several models have been proposed to explain the behaviour of the lithosphere-atmosphere-ionosphere coupled system before earthquake occurrences. Models deal with the interactions between the acoustic and gravity waves due to thermodynamical processes in the Earth's crust.

Sources such as sub-surface and nuclear explosions, large volcanic eruptions, strong earthquakes and rocket launches are known to excite atmospheric waves (Blanc, 1985). They generate acoustic and gravity-acoustic waves that propagate laterally and upward, away from the source. These perturbations eventually reach the ionospheric layers. Aerosols and metallic ions emitted in the atmosphere may have affected the ionosphere above the seismic regions (Pulinets and Boyarchuk, 2004).

Also the penetration of an electrostatic field, from a source located in the lithosphere into the ionosphere, has been investigated. The electrostatic problem is solved numerically for a medium with an inhomogeneous anisotropic conductivity coupled to an effective upper boundary condition. The results show that the electric field in the ionosphere's Dlayer can effectively change the parameters of the lower ionosphere. It is concluded that the atmospheric conductivity at $60 \mathrm{~km}$ can change by $30-70 \%$ as a result of electrostatic perturbations, created before the onset of earthquakes, and the penetration of an electrostatic field from the lithosphere into the ionosphere above $60 \mathrm{~km}$ is much better at nighttime than during the day (Grimalsky et al., 2003). However, the recent studies by Ampferer et al. (2010) and Denisenko et al. (2008) showed the difficulty and the complexity in studying the physical penetration mechanism of the electric field from the Earth's surface, through the atmosphere-ionosphere layers and to its detection in space by satellites.

In Sect. 2 of this paper, we describe the total electron content and the electric field measurements observed above the L'Aquila region in the time interval from 15 March to 12 April 2009. The main aim is to show the variations of those physical parameters before and after the occurrence of the earthquakes on 6 April 2009. In Sect. 3, the Ap index and ACE ion density are considered and the solar and geomagnetic activities are analysed. We discuss our findings and we summarize our main results in the two last sections.

\section{Data investigation}

\subsection{TEC maps}

TEC is a descriptive quantity for the ionosphere of the Earth. It is defined as the total number of electrons present along the path between two points. The ionospheric models are based on the so-called Single Layer Model (SLM), which assumes that all free electrons are concentrated in a thin shell of infinitesimal thickness at $450 \mathrm{~km}$.

The determination of the vertical TEC is based on spherical harmonics up to a degree and order 15 and is produced on a regional scale with 19 contributing GPS stations. The TEC maps have an interpolated spatial resolution of $1^{\circ} \times 1^{\circ}$ and 


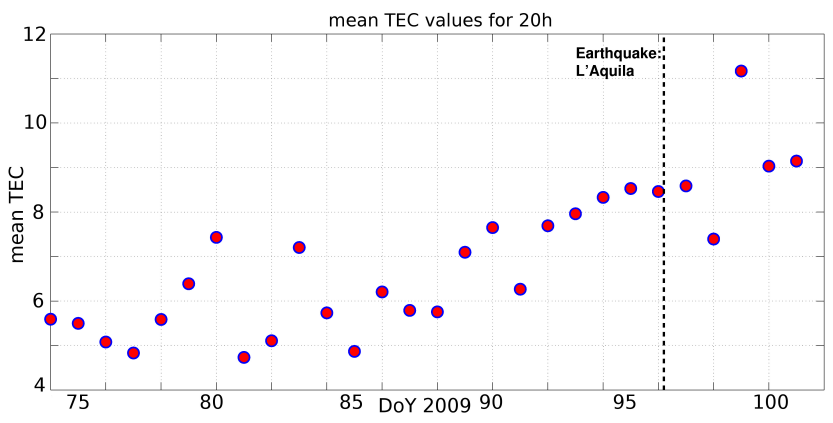

Fig. 1. Mean TEC values at $20 \mathrm{~h}$ UT from GPS measurements (corresponding to DEMETER transitions). Accuracy 0.5 TECU, derived from regional GNSS stations.

are produced every $15 \mathrm{~min}$. Figure 1 shows a time series of the mean TEC values at $20 \mathrm{~h}$ (UTC) for a period around the EQ. It is interesting to note the random variation of the mean TEC from 15 to 29 March. From the beginning of April and until the earthquake occurrence, we find a clear progressive increase of the TEC values. A few days before the EQ, we observed a stagnancy at a relatively higher TEC value.

\subsection{Ionospheric VLF sounding above L'Aquila region}

We analyse the electric field intensity variations recorded on board DEMETER micro-satellite by ICE experiment. It was launched on 29 June 2004, with a synchronous solar quasi-circle orbit, an inclination of $98.3^{\circ}$ and a low-altitude of about $710 \mathrm{~km}$ (Parrot et al., 2006). The ICE experiment is devoted to the investigation of the wave electric field in four separate frequency channels: DC/ULF $(0.15 \mathrm{~Hz}), \mathrm{ELF}$ $(15 \mathrm{~Hz}-1 \mathrm{kHz}), \operatorname{VLF}(15 \mathrm{~Hz}-17.4 \mathrm{kHz})$ and HF $(10 \mathrm{kHz}-$ $3.175 \mathrm{MHz}$ ). We use the so-called survey mode which leads to record low bit rate data all around the Earth at invariant latitudes less than $65^{\circ}$ (Berthelier et al., 2006). The spectral pixel resolution is about $2.048 \mathrm{~s}$ and $19.53 \mathrm{~Hz}$.

The used method consists of selecting orbits when DEMETER micro-satellite was above L'Aquila (Latitude $=42.38^{\circ} \mathrm{N}$, Longitude $=13.32^{\circ} \mathrm{E}$ ). The period of investigation is from 15 March to 11 April 2009. During this time interval, gaps occurred in the DEMETER data at two occasions: (a) 23 and 24 March, and (b) 6 and 7 April. A "rectangle" area centred on L'Aquila region is considered with latitude and longitude intervals from $32.38^{\circ}$ to $52.38^{\circ} \mathrm{N}$ and $8.32^{\circ}$ to $18.32^{\circ} \mathrm{E}$. This leads to daily collected measurements of ICE experiment mainly when the satellite is on the nightside of the Earth at about 22:00 LT. In this study, we select two frequencies $f_{1}=16652.5 \mathrm{~Hz}$ and $f_{2}=5195.313 \mathrm{~Hz}$ and analyse the corresponding intensity levels above L'Aquila. The first frequency is the closest frequency to the DFY-German transmitter emitting at a frequency of $16.56 \mathrm{kHz}$ and localised at a longitude of $13^{\circ} \mathrm{E}$, and a latitude of $52.5^{\circ} \mathrm{N}$. Figure 2 shows the averaged inten-

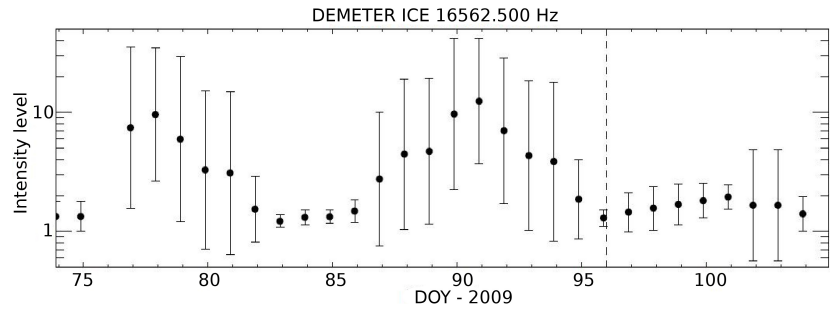

Fig. 2. Variation of the DEMETER observed signal at the frequency of $16652.5 \mathrm{~Hz}$ (the closest frequency to the German transmitter signal $16560 \mathrm{~Hz}$ ) versus the day of the year 2009 (from 15 March to 11 April 2009). The day of the EQs is indicated by a vertical dashed line.

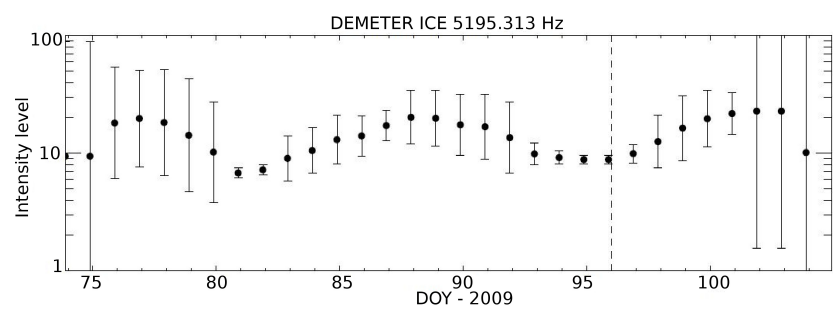

Fig. 3. Variation of the whistlers VLF emissions observed daily above L'Aquila regions by ICE experiment on board DEMETER micro-satellite at a frequency of $5195.313 \mathrm{~Hz}$.

sity variation of the transmitter signal as recorded on board DEMETER micro-satellite. Each point indicates the averaged intensity derived from a cluster of measurements observed during $12 \mathrm{~h}$. Afterwards, we compute the corresponding standard deviation obtained from a sample population of 5 elements around the interpolated point. Similar data processing is performed in the case of the second frequency $\left(f_{2}\right)$ as displayed in Fig. 3.

Combining Fig. 2 and 3 it is interesting to note that the VLF signals is decreasing a few days before the EQ occurrence. It is mainly the case of the amplitude of the transmitter signal where we note a drop of one order of magnitude.

\section{Geomagnetic variations}

For arithmetical and statistical manipulations, a linear threehourly range Ap index has been derived by Bartels et al. (1939) from the logarithmic Kp index describing the magnetic activity (Jacobs, 1989). The Ap index ranges from 0 to 400 , from quiet to severe storm. Figure 4 (upper panel) shows the Ap index during the investigation period, including the day of the EQ. Small amplitudes of approximately 15 before and 18 after the EQ can be observed on 27 March and 10 April, which indicate unsettled and active geomagnetic circumstances, respectively. The Ap index is found, on average, of about 3 in the time interval from 1 to 6 April 2010. The geomagnetic activity was predominantly quite low 

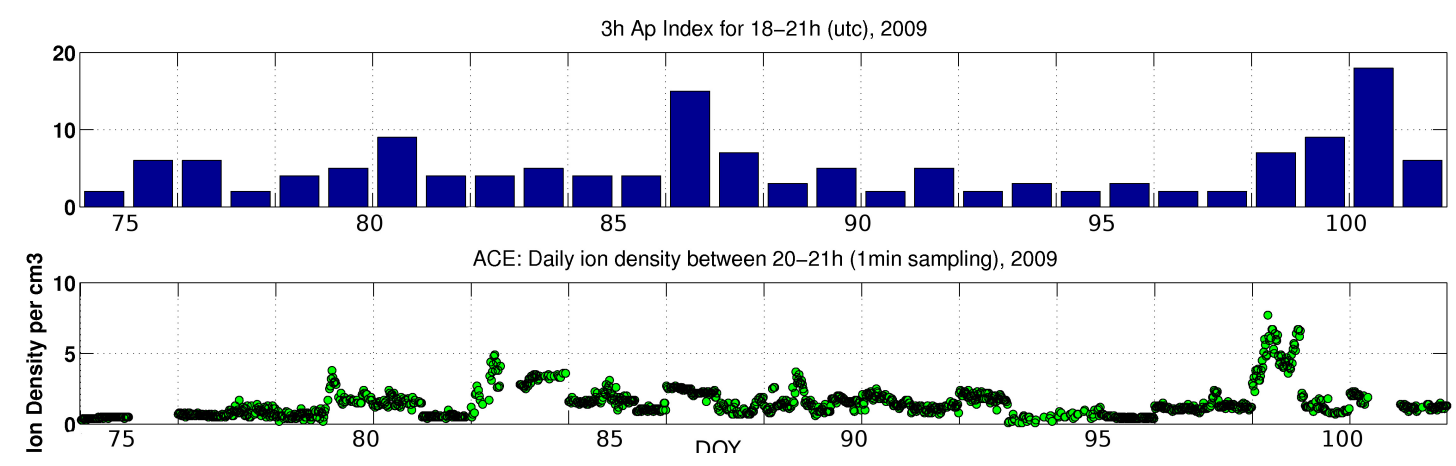

Fig. 4. Ap index (top panel) and ion density (bottom panel) measurements recorded during the DEMETER orbital transition periods above L'Aquila regions.

when it is compared to other periods, like the end of March and after EQ. Compatible to this, a time series of ion density recorded from the Advanced Composition Explorer (ACE) is shown in Fig. 4 (lower panel). ACE is operating close to the L1 Lagrange point to study comprising energetic particles from the solar wind and interplanetary medium.

\section{Discussion}

We report on TEC and VLF measurements related to L'Aquila earthquakes. In both cases, we have found a particular variations of those parameters before and after the occurrence of the seismic events. In the following section, we discuss our outcomes and their relations to particular effects which took place in the ionosphere.

\subsection{VLF anomalies as a consequence of TEC ionospheric disturbance}

The combination of GPS and DEMETER space observations enables us to check the behaviour of the ionosphere above the L'Aquila seismic regions.

First the GPS satellites provide electronic density content above the L'Aquila region. In normal cases, the TEC values are correlated to the geomagnetic variations and the ACE data, because all of them are triggered by solar events. However, we find that before the L'Aquila earthquake occurrence the TEC increased but the two other parameters (Ap and ACE) do not show similar variations. It is supposed that the electron number enhancements must have another source than the sun and might be a regional phenomenon related to the EQ.

Secondly DEMETER micro-satellite leads us to measure the electric field variation during its orbital transits above the L'Aquila region. We find that the VLF amplitude signal showed a drop in the intensity level at two frequencies, $f_{1}=16652.5 \mathrm{~Hz}$ and $f_{2}=5195.313 \mathrm{~Hz}$. It is noted that the decreases are different when we combine the signal related to each frequency. In the case of DFY-German transmitter frequency (i.e., $f_{1}$ ), the intensity started to decrease on 2 April $(\mathrm{DOY}=91)$ and reached its minimum on 6 April $($ DOY $=96)$ (see Fig. 2). The intensity level associated to the second frequency decreased a few days earlier, on 30 March $(\mathrm{DOY}=89)$ and attained minima on 5 April (DOY = 95) (see Fig. 3). The common period is found to be between 2 and 5 April 2009. During this period of 4 days the TEC progressively increases and reaches maxima one day before and after EQ. Probably the drop of the VLF signals is a consequence of the ionospheric disturbances.

\subsection{Unlike VLF signal behaviour in the disturbed ionosphere}

We find that the drop in signals needs shorter and a longer time intervals for VLF $f_{1}$ and $f_{2}$ frequencies, respectively. The behaviour of each frequency is not alike. On the one side, the signal of the transmitter $\left(f_{1}\right)$, emitted from the German ground-based station, is "damped" in 5 days reaching minima one day before the EQ. On the other side, the socalled whistler emission $\left(f_{2}\right)$, generated mainly in the magnetosphere, decreased in 7 days and attained minima the day of the L'Aquila seismic event. This indicates that the whistler emissions suffer the earthquakes ionospheric disturbance two days before the transmitter signals. Since the whistler are magnetospheric emissions, they propagate along the Earth's magnetic field at altitudes higher than the D- and E-layers. In this case the TEC measurements may not be adapted to remote layers higher than D-E ionospheric layers.

However, the TEC and VLF transmitter measurements showed increase and decrease variations in the same time interval (i.e., from $2(\mathrm{DOY}=92)$ to $5(\mathrm{DOY}=96)$ April), respectively. This suggests that the TEC measurements of Dand E-layers can be considered as a map out of the ionospheric activity. Despite the fact that the electronic density of GPS satellites indicates the sum of electrons between the DEMETER micro-satellite and the ground. 


\section{Conclusions}

We analyse the Total Electron Content (TEC) and Very Low Frequency (VLF) space measurements derived from Global Positioning System (GPS) and DEMETER satellites, respectively. We show anomaly enhancements in TEC measurement a few days before the L'Aquila earthquakes. Drop of intensity levels of VLF electric field occur in quasi-similar time intervals, i.e., from 2 to 5 April. The TEC enhancement is at the origin of the drop of both VLF intensity levels. The ray paths of VLF emissions are deviated during their propagations in the turbulent ionosphere. The VLF signal level drops because it only occasionally reaches the DEMETER satellite. Further investigations should provide a quantitative description of the VLF wave propagation through enhanced plasma due to seismo-ionospheric disturbance.

Acknowledgements. We acknowledge C. N. E. S. for the use of the DEMETER data, and are thankful to Jean-Jacques Berthelier who provided us with data from the ICE experiment.

Edited by: M. E. Contadakis

Reviewed by: I.-A. Moldovan and J. Blecki

\section{References}

Akhoondzadeh, M., Parrot, M., and Saradjian, M. R.: Electron and ion density variations before strong earthquakes $(M>6.0)$ using DEMETER and GPS data, Nat. Hazards Earth Syst. Sci., 10, $7-$ 18, doi:10.5194/nhess-10-7-2010, 2010.

Ampferer, M., Denisenko, V. V., Hausleitner, W., Krauss, S., Stangl, G., Boudjada, M. Y., and Biernat, H. K.: Decrease of the electric field penetration into the ionosphere due to low conductivity at the near ground atmospheric layer, Ann. Geophys., 28, 779-787, doi:10.5194/angeo-28-779-2010, 2010.

Bartels, J., Heck, N. H., and Johnston, H. F.: The three hourly range index measuring geomagnetic activity, Terr. Magn. Atmos. Electr., 44, 411-454, 1939.

Berthelier, J. J., Godefroy, M., Leblanc, F., Malingre, M., Menvielle, M., Lagoutte, D., Brochot, J. Y., Colin, F., Elie, F., Legendre, C., Zamora, P., Benoist, D., Chapuis, Y., Artru, J., and Pfaff, R.: ICE, the electric field experiment on DEMETER, Planet. Space Sci., 54(5), 456-471, doi:10.1016/j.pss.2005.10.016, 2006.

Blanc, E.: Observations in the upper atmosphere of infrasonic waves from natural or artificial sources: a summary, Ann. Geophys., 3, 673-688, 1985, http://www.ann-geophys.net/3/673/1985/.

Boudjada, M. Y., Schwingenschuh, K., Biernat, H. K., Berthelier, J. J., Blecki, J., Parrot, M., Stachel, M., Aydogar, ., Stangl, G., and Weingrill, J.: Similar behaviors of natural ELF/VLF ionospheric emissions and transmitter signals over seismic Adriatic regions, Nat. Hazards Earth Syst. Sci., 8, 1229-1236, doi:10.5194/nhess8-1229-2008, 2008.
Boudjada, M. Y., Schwingenschuh, K., Döller, R., Rohznoi, A., Parrot, M., Biagi, P. F., Galopeau, P. H. M., Solovieva, M., Molchanov, O., Biernat, H. K., Stangl, G., Lammer, H., Moldovan, I., Voller, W., and Ampferer, M.: Decrease of VLF transmitter signal and Chorus-whistler waves before l'Aquila earthquake occurrence, Nat. Hazards Earth Syst. Sci., 10, 1487 1494, doi:10.5194/nhess-10-1487-2010, 2010.

Calais, E. and Minster, J. B.: GPS detection of ionospheric TEC perturbations following the January 17, 1994, Northridge earthquake, Geophys. Res. Lett., 22(9), 1045-1048, 1995.

Calais, E. and Amarjargal, S.: New constraints on current deformation in Asia from continuous GPS measurements at Ulan Baatar, Mongolia, Geophys. Res. Lett., 27(10), 1527-1530, doi:10.1029/1999GL005444, 2000.

Davies, K.: Ionospheric Radio, Peter Pergrinus, London, 1990.

Denisenko, V. V., Boudjada, M. Y., Horn, M., Pomozov, E. V., Biernat, H. K., Schwingenschuh, K., Lammer, H., Prattes, G., and Cristea, E.: Ionospheric conductivity effects on electrostatic field penetration into the ionosphere, Nat. Hazards Earth Syst. Sci., 8, 1009-1017, doi:10.5194/nhess-8-1009-2008, 2008.

Grimalsky, V. V., Hayakawa, M., Ivchenko, V. N., Rapoport, Y. G., and Zadorozhnii, V. I.: Penetration of an electrostatic field from the lithosphere into the ionosphere and its effect on the Dregion before earthquakes, J. Atmos. Sol.-Terr. Phy., 65(4), 391-407, doi:10.1016/S1364-6826(02)00341-3, 2003.

Hayakawa, M., Molchanov, O. A., Ondoh, T., and Kawai, E.: The precursory signature effect of the Kobe earthquake on subionospheric VLF signals, J. Comm. Res. Lab., 43, 169-180, 1996.

Hayakawa, M., Molchanov, O. A., Kodama, T., Afonin, V. V., and Akentieva, O. A.: Plasma density variations observed on a satellite possibly related to seismisity, Adv. Space Res., 26(8), 12771280, doi:10.1016/S0273-1177(99)01224-7, 2000.

Jacobs, J. A.: Geomagnetism, Volume 3, Academic Press, 1989.

Liu, J. Y., Chen, Y. I., Pulinets, S.A., Tsai, Y. B., and Chuo, Y. J.: Seismo-ionospheric signatures prior to $\mathrm{M} \geq 6.0$ Taiwan earthquakes, Geophys. Res. Lett., 27(19), 3113-3116, doi:10.1029/2000GL011395, 2000.

Liu, J. Y., Chen, Y. I., Chuo, Y. J., and Tsai, H. F.: Variations of ionospheric total electron content during the ChiChi earthquake, Geophys. Res. Lett., 28(7), 1383-1386, doi:10.1029/2000GL012511, 2001.

Liu, J. Y., Chuo, Y. J., Pulinets, S. A., Tsai, H. F., and Zeng, X. P.: A study on the TEC perturbations prior to the Rei-Li, Chi-Chi and Chia-Yi earthquakes, Seismo Electromagnetics: LithosphereAtmosphere-Ionosphere Coupling, edited by: Hayakawa, M. and Molchanov, O. A., TERRAPUB, Tokyo, 297301, 2002.

Molchanov, O., Rozhnoi, A., Solovieva, M., Akentieva, O., Berthelier, J. J., Parrot, M., Lefeuvre, F., Biagi, P. F., Castellana, L., and Hayakawa, M.: Global diagnostics of the ionospheric perturbations related to the seismic activity using the VLF radio signals collected on the DEMETER satellite, Nat. Hazards Earth Syst. Sci., 6, 745753, doi:10.5194/nhess-6-745-2006, 2006.

Molchanov, O. and Hayakawa, M.: Seismo-electromagnetics and related phenomena: History and latest results, TERRAPUB, Tokyo, 2008.

Muto, F., Yoshida, M., Horie, T., Hayakawa, M., Parrot, M., and Molchanov, O. A.: Detection of ionospheric perturbations associated with Japanese earthquakes on the basis of reception of LF transmitter signals on the satellite DEMETER, Nat. Hazards 
Earth Syst. Sci., 8, 135-141, doi:10.5194/nhess-8-135-2008, 2008.

Parrot, M.: Electromagnetic noise due to earthquakes, in: Handbook of Atmospheric Electrodynamics, Vol. II, edited by: Volland, H., CRC Press, Boca Raton, FL, 95-116, 1995.

Parrot, M., Benoist, D., Berthelier, J.J., Blecki, J., Chapuis, Y., Colin, F., Elie, F., Fergeau, P., Lagoutte, D., Lefeuvre, F., Legendre, C., Leveque, M., Pincon, J. L., Poirier, B., Serana, H. C., and Zamora, P.: The magnetic field experiment IMSC and its data processing onboard DEMETER: Scientific objectives, description and first results, Planet. Space Sci., 54(5), 441-455, doi:10.1016/j.pss.2005.10.015, 2006.

Pulinets, S. A.: Seismic activity as a source of the ionospheric variability, Adv. Space Res., 22(6), 903-906, doi:10.1016/S02731177(98)00121-5, 1998.
Pulinets, S. A. and Boyarchuk, K. A.: Ionospheric Precursors of Earthquakes, Springer, Berlin, Heidelberg, New York, 2004.

Rozhnoi, A., Molchanov, O., Solovieva, M., Gladyshev, V., Akentieva, O., Berthelier, J. J., Parrot, M., Lefeuvre, F., Hayakawa, M., Castellana, L., and Biagi, P. F.: Possible seismo-ionosphere perturbations revealed by VLF signals collected on ground and on a satellite, Nat. Hazards Earth Syst. Sci., 7, 617-624, doi:10.5194/nhess-7-617-2007, 2007.

Zhao, B., Wang, M., Yu, T., Wan, W., Lei, J., and Liu, L.: Is an unusual large enhancement of ionospheric electron density linked with the 2008 great Wenchuan earthquake?, J. Geophys. Res., 113, A11304, doi:10.1029/2008JA013613, 2008. 